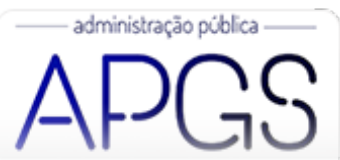

Administração Pública e Gestão Social ISSN: 2175-5787

apgs@ufv.br

Universidade Federal de Viçosa

Brasil

\title{
Valores Públicos e Contratação de Serviços Terceirizados: Desafios no Setor Público
}

Maria Leal Santos, Natália; Meirelles Andrade, Daniela; Braga de Lima, Juvencio Valores Públicos e Contratação de Serviços Terceirizados: Desafios no Setor Público

Administração Pública e Gestão Social, vol. 11, núm. 3, 2019

Universidade Federal de Viçosa, Brasil

Disponível em: http://www.redalyc.org/articulo.oa?id=351559268009

Esta obra está bajo una Licencia Creative Commons Atribución-NoComercial-SinDerivar 3.0 Internacional. 


\title{
Valores Públicos e Contratação de Serviços Terceirizados: Desafios no Setor Público
}

\author{
Public Values and Contracts for Outsourced Services: Challenges in the Public Sector \\ Valores Públicos y Contratación de Servicios Tercerizados: Desafíos en el Sector Público
}

Natália Maria Leal Santos

Universidade Federal de Lavras, Brasil

nateleal@gmail.com

Daniela Meirelles Andrade

Universidade Federal de Lavras, Brasil

daniela.andrade@ufla.br

Juvencio Braga de Lima

Universidade Federal de Lavras, Brasil

jbragadelima@gmail.com
Redalyc: http://www.redalyc.org/articulo.oa? $\mathrm{id}=351559268009$

Recepção: 25 Agosto 2017

Aprovação: 29 Novembro 2017

Publicado: 01 Julho 2019

\section{Resumo:}

A terceirização é uma prática que se intensificou no setor público a partir da reforma do Estado. Diante da literatura percebeuse que valores públicos constitucionais podem ser perdidos quando a responsabilidade pela execução é transferida do empregador (o governo) para uma empresa privada. Diante dessa problemática, este artigo tem como objetivo analisar editais, contratos e a prestação de serviços terceirizados em uma instituição pública federal localizada em Minas Gerais, a fim de verificar a aplicação dos princípios constitucionais da administração pública (legalidade, impessoalidade, moralidade, publicidade e eficiência) na terceirização. Para atingir os objetivos da pesquisa foi realizado um estudo de caso. Foram utilizados dados primários e secundários, os quais foram submetidas à Análise de Conteúdo. Os resultados da pesquisa evidenciaram que os valores públicos são perdidos e negligenciados na execução dos serviços contratados. Além disso, a adoção da terceirização pode possibilitar o afloramento dos vícios da administração pública brasileira.

Palavras-chave: Administração Pública, Valor Público, Contratos, Terceirização.

\section{Abstract:}

Outsourcing is a practice that has intensified in the public sector since the reform of the Brazilian State. In the literature it has been realized that constitutional public values can be lost when the responsibility for the execution is transferred from the government to a private company. In the face of this problem, this article aims to analyze notices, contracts and the provision of outsourced services in a Federal public institution located in the state of Minas Gerais, Brazil, in order to verify the application of the constitutional principles of public administration (legality, impersonality, efficiency) in outsourcing services. To achieve the research objectives, a case study was carried out. Primary and secondary data were used, which were submitted to content analysis. The results of the research showed that public values are lost and neglected in the execution of the contracted services. In addition, the adoption of outsourcing can make the emergence of bad habits of the Brazilian public administration possible.

KEYWORDS: Public Administration, Public Value, Contracts, Outsourcing.

\section{Resumen:}

La subcontratación es una práctica que se ha intensificado en el sector público a partir de la reforma del Estado brasileño. Ante la literatura se percibió que valores públicos constitucionales pueden ser perdidos cuando la responsabilidad por la ejecución es transferida del empleador, el gobierno, a una empresa privada. En el marco de esta problemática, este artículo tiene como objetivo analizar ediciones, contratos y la prestación de servicios tercerizados en una institución pública federal ubicada en Minas Gerais, un estado brasileño, a fin de verificar la aplicación de los principios constitucionales de la administración pública (legalidad, impersonalidad, moralidad, publicidad y eficiencia) en la subcontratación. Para alcanzar los objetivos de la investigación se realizó un estudio de caso y se utilizaron datos primarios y secundarios, los cuales fueron sometidos al análisis de contenido. Los resultados 
de la investigación han demonstrado que los valores públicos se pierden cuando se descuida en la ejecución de los contratos de servicios. Además, la adopción de la subcontratación puede posibilitar el afloramiento de los vicios de la administración pública brasileña.

Palabras Clave: Administración Pública, Valor Público, Contratos, Tercerización.

\section{INTRODUÇÃO}

A tendência cada vez mais crescente da terceirização do trabalho no setor público tem levantado discussões e desafios tanto para profissionais quanto para pesquisadores. Se por um lado seus defensores alegam as promessas de eficiência, por outro lado ainda há muito a se discutir sobre terceirização no setor público.

Em seus aspectos históricos, a terceirização originou-se no setor privado como um instrumento de flexibilização das atividades empresariais, tornando-se um fenômeno mundial amplamente difundido nas sociedades capitalistas (Muta, Alves \& Vergna, 2010), mas passou a ser disseminada intensamente no setor público brasileiro a partir da reforma do Estado e da introdução do modelo gerencial de administração ao longo da década de 1990.

A difusão da terceirização no setor público está relacionada ao modelo gerencial (Silva, 2011), de modo que os serviços terceirizados passaram a ser contratados via processos licitatórios. Ressalvadas as hipóteses de dispensa ou inexigibilidade de licitação, esse processo, geralmente, é realizado por uma espécie de leilão às avessas, o qual é denominado pregão: Vence a proposta que ofertar o serviço pelo menor preço possível (Lei n. 8.666, 1993; Freitas \& Maldonado, 2013).

É possível tecer diversas críticas a respeito da terceirização que é um tema polêmico e controverso, uma vez que os determinantes do sucesso da terceirização no setor público não são conhecidos (Jensen \& Stonecash, 2004). Em se tratando do setor público, Silva (2011) destaca que, perante o usuário, é a administração pública que aparece como prestadora do serviço. O prestador do serviço é apenas o executor material para o poder público contratante. Assim, o poder público é o sujeito, diretamente relacionado com os usuários e continua sendo responsável direto pelos serviços. (Mello, 2010).

$\mathrm{Na}$ Constituição Federal de 1988 estão fixados os requisitos para a execução de serviços públicos. Nesse sentido, julga-se fundamental a observância dos princípios nela descritos, quais sejam: Legalidade, impessoalidade, moralidade, publicidade e eficiência (Constituição da República Federativa do Brasil, 1988). A terceirização pode trazer consequências, conforme alertam Rosenbloom e Piotrowski (2005), bem como Battaglio e Ledvinka (2009), para a possibilidade de que os valores do Direito Constitucional possam ser perdidos quando a responsabilidade pela execução é transferida do empregador, o governo, para uma empresa privada em função da distância entre interesse público e privado.

Diante dessa problemática, este artigo tem como objetivo principal analisar editais, contratos e a prestação de serviços terceirizados em uma instituição pública federal localizada em Minas Gerais, investigando suas características quanto à aplicação dos princípios da administração pública (legalidade, impessoalidade, moralidade, publicidade e eficiência). Especificamente pretende-se: a) analisar os editais de licitação utilizados na contratação de serviços terceirizados e os contratos celebrados com as empresas vencedoras a fim de verificar as exigências contratuais; b) analisar a presença ou ausência de valores públicos (princípios constitucionais da administração pública) nas práticas de terceirização no setor público. Os resultados da pesquisa evidenciaram que os valores públicos são perdidos e negligenciados na execução dos serviços contratos. Além disso, a adoção da terceirização pode possibilitar o afloramento dos vícios da administração pública brasileira. 


\section{PRINCÍPIOS DA ADMINISTRAÇÃO PÚBLICA: UMA VISÃo A PARTIR DOS VALORES PÚBLICOS}

O princípio da supremacia do interesse público sobre o interesse privado é precípuo de qualquer Estado, constituindo o princípio geral inerente a qualquer sociedade sendo condição básica de sua existência como também um pressuposto lógico de convívio social (Mello, 2010). A supremacia do interesse público está relacionada às possíveis colisões entre interesse público e interesse privado. Dessa maneira, quando tais interesses entram em rota de colisão, o primeiro prevalece sobre o segundo. Para Carvalho (2010), a observância do interesse público não nega ou desrespeita o interesse privado, mas quando há divergências e são bem comuns é que o interesse público sobrepõe o privado, pois o Estado tem que defender os interesses da coletividade atuando no sentido de favorecer o bem comum e é por isso que tem que fazer prevalecer o interesse público (Di Pietro, 2010b).

Carvalho (2010) destaca que atualmente é necessário pensar no princípio da supremacia do interesse público para adequá-lo aos novos elementos da modernidade, ou seja, aos novos arranjos organizacionais, ajustando-o para que os interesses se harmonizem para que sejam superados os confrontos ou mesmo sejam evitados, uma vez que, atualmente, a administração pública se reveste do interesse público, mas se fundamenta também na administração privada (Oliveira, 2012).

A administração pública pode ser entendida como uma ação gerencial voltada para o interesse público, fundamentada nos princípios constitucionais descritos no art. 37 da Constituição Federal brasileira (Constituição da República Federativa do Brasil, 1988), quais sejam: Legalidade, impessoalidade, moralidade, publicidade e eficiência. A razão de ser dos princípios é nortear toda a prática administrativa do setor público (Pazzaglini, 2008).

Conforme destacado por Meirelles (2009), “na Administração Pública não há liberdade nem vontade pessoal. Enquanto na administração particular é lícito fazer tudo que a lei não proíbe, na administração pública só é permitido fazer o que a lei autoriza”. Para Pazzaglini (2008), o princípio da legalidade é direito fundamental de toda pessoa. Ele determina que a administração pública pode atuar somente em conformidade com a lei, cabendo aos particulares/privados apenas a sua não contrariedade. $\mathrm{O}$ princípio da legalidade contrapõe-se às tendências personalistas bem como às formas de poder autoritário, constituindo um antídoto do poder oligárquico.

A impessoalidade expressa uma conduta imparcial nas ações, tendo como propósito o atendimento do interesse público. Nesse sentido, a administração pública não pode praticar atos visando interesses pessoais ou subordinar-se à conveniência de qualquer indivíduo (Pazzaglini, 2008). Segundo Paulo e Alexandrino (2015), a impessoalidade na atuação administrativa deve impedir a prática de atos que visem atender interesses do agente público ou de terceiros. Nesse sentido, os autores destacam que o princípio da impessoalidade inibe perseguições ou favorecimentos, discriminações benéficas ou prejudiciais aos administrados.

Conforme Pazzaglini (2008), a moralidade está relacionada à ética na conduta administrativa, devendo submeter-se ao interesse coletivo. Segundo Di Pietro (2010a), mesmo em consonância com a lei, haverá ofensa ao princípio da moralidade administrativa quando o comportamento do administrado que se relaciona com a administração pública juridicamente afronta a moral, as regras de boa administração, os princípios de justiça e de equidade, bem como a ideia comum de honestidade.

Nohara (2014) destaca que tanto a impessoalidade quanto a moralidade encontram dificuldades de efetivação no contexto brasileiro na medida em que o histórico do País é marcado pelos resquícios de paternalismo e clientelismo nos espaços públicos, por isso, o princípio da moralidade é um instrumento necessário e imprescindível para defesa do ideário republicano que é avesso à ideia de confusão entre patrimônio público e a coisa privada. O princípio da moralidade tem como finalidade coibir, além do 
nepotismo direto, como também o indireto manifestado em indicações cruzadas, triangulares ou de reciprocidades.

Em relação à publicidade, Mello (2010) destaca que esse princípio busca manter a plena transparência do comportamento administrativo como meio de não haver ocultamento dos assuntos de interesse coletivo. Para Nohara (2014), ele gera credibilidade pela transparência, pois os cidadãos têm conhecimento das ações públicas. Pazzaglini (2008) ressalta que abrange o acesso aos fatos, atos, contratos, normas, decisões e informações em geral. A publicidade é requisito essencial à transparência da administração da coisa pública. Conforme Meirelles (2009), os contratos públicos devem ser divulgados a qualquer pessoa que desejar conhecê-los, não podendo ser ocultados sob o argumento que são sigilosos.

A eficiência é norteada para a busca de resultados de modo rápido e preciso, a fim de satisfazer as necessidades da população (Pazzaglini, 2008). Para o autor, é dever do agente público agir com eficiência na medida em que sua conduta deve, além de obedecer a lei e ser honesta, deve ser também produtiva, profissional e adequada ao exercício funcional visando à satisfação do interesse público. Para Di Pietro (2010a), assim como para Paulo e Alexandrino (2015), o princípio da eficiência pode ser dividido em dois aspectos: Qualidade da atuação do agente público, que deve procurar obter um padrão de excelência no desempenho de suas atribuições, e modo de organizar e estruturar os órgãos e entidades integrantes da administração pública, visando racionalidade na prestação dos serviços públicos.

Pazzaglini (2008) destaca que nenhuma regra tem o poder de confrontar ou contrariar diretrizes vinculadas pelos princípios constitucionais, os quais são impositivos e coercivos para toda a sociedade brasileira, regendo o comportamento tanto de seus integrantes (administrados) como de seus representantes (administradores). Assim, considerando o caráter público da atividade terceirizada, é possível afirmar que uma empresa privada terceirizada deve também estar atenta a essa orientação de não contrariar tais princípios.

\section{SERVIÇOS PÚBLICOS E TERCEIRIZAÇÃO}

Os serviços públicos não são apenas atividades prestadas diretamente pelo Estado, conforme destacado por Carvalho (2009). Segundo o autor, os serviços públicos também são aqueles delegados pelo Estado para que sejam satisfeitas as necessidades essenciais e secundárias da coletividade. Dessa forma, a prestação de serviços públicos pode ser realizada pela atuação direta do Estado ou por uma atuação indireta (Constituição da República Federativa do Brasil, 1988).

A adoção do modelo de administração gerencial a partir dos anos 1990, no governo de Fernando Henrique Cardoso, foi um mecanismo de reforma no setor público que, dentre outros elementos, previa a privatização e a terceirização de serviços públicos, com vistas a enxugar o tamanho do Estado, diminuir gasto e atingir maior eficiência (Motta, 2007). Ainda que o modelo não tenha sido implementado de maneira tal como idealizada, foi a partir da reforma que o desenvolvimento das relações entre o setor público e privado ganhou destaque e o Estado brasileiro começou a enxugar seu quadro de servidores e transmitir suas atividades consideradas não estratégicas/exclusivas para a iniciativa privada (Freitas \& Maldonado, 2013). Diante desse cenário, a administração pública recorreu à flexibilização dos meios de prestação de serviços, utilizando a terceirização de serviços como alternativa possível para responder à crescente demanda da sociedade por serviços públicos.

A terceirização tornou-se um meio de desverticalizar, ou seja, enxugar o tamanho do Estado, com o objetivo de tornar as organizações mais flexíveis sob o argumento de facilitar as mudanças requeridas pela sociedade. Para Di Pietro (2009), a terceirização está relacionada à ideia de parceria. Nesse sentido, a autora destaca a seguintes vantagens: Concentração na execução da atividade-fim por parte da empresa tomadora do serviço; a especialização da empresa contratada para executar as atividades não finalísticas; diminuição de gastos com os encargos trabalhistas e previdenciários o que tornaria possível reduzir o preço do produto ou serviço; simplificação da estrutura, por meio da redução de níveis hierárquicos. Costa (1994) também destaca que a terceirização propicia a geração de emprego. 
No setor público, Battaglio e Ledvinka (2009) destacam que existem alguns riscos específicos, os quais gestores públicos devem estar cientes quando confrontados com a decisão de fazer ou comprar, ou seja, terceirizar ou não, entre os quais os autores destacam que a terceirização reforça a importância da satisfação de grandes interesses de organizações privadas e diminui a importância de cada trabalhador.

Magalhães, Carvalho e Saraiva (2011) mencionam que existem argumentos contrários à terceirização bastante consideráveis, como a dificuldade de se encontrar no mercado empresas terceiras suficientemente qualificadas para assumir as atividades a serem terceirizadas. Segundo os autores, a maioria dessas empresas não dispõe de capacidade administrativa e financeira necessárias para investir na sua expansão, como também não investem em capacitação e qualificação de seus funcionários. Nesse sentido, a crítica contundente resulta do relato de Lourenço (2015), quando afirma que as empresas terceiras fazem uso do trabalho desqualificado.

Para Araújo (2005), além de uma seleção criteriosa de pessoal, também é imprescindível realizar o processo de avaliação de desempenho como forma de atestar a adequação da seleção ao desempenho e identificar necessidades de capacitação. Nesse sentido, Silva e Souza (2004) afirmam que o funcionário terceirizado que presta serviço na administração pública deve ser avaliado na consecução de suas atividades. Contudo, destacam que a falta de treinamento e qualificação são fatores preocupantes que podem desencadear uma inadequação de perfil profissional, gerando alta rotatividade de funcionários.

Outro aspecto analisado por Silva e Souza (2004) é a possibilidade de que a terceirização possa vir a servir de instrumento para burlar as exigências constitucionais. Nesse sentido, não se deveria utilizar a flexibilização da estrutura pública para viabilizar a infiltração de contratações de parentes e de funcionários para exercer funções no setor público.

Conforme Silva e Souza (2004), a idoneidade da empresa contratada é fundamental na parceria entre Estado e iniciativa privada, para que não prevaleçam apenas os interesses do segundo. De acordo com os autores, "[...] todos os direitos e obrigações contratuais que deverão ser firmados, aliados ao compromisso moral, que venha em contrapartida de uma boa parceria”. Assim, os autores defendem a ideia de que se deve buscar parceiros com interesse público, por meio de processo licitatório, os quais deverão assumir a responsabilidade pela execução dos serviços públicos.

Para Cavalcante (2015), é necessário analisar com cuidado a terceirização. Segundo o autor, a terceirização é ilícita quando existente nos quadros de pessoal do órgão, cargo ou emprego que possa desempenhar a atribuição objeto da contratação. "Isso se dá não apenas com base na legislação infraconstitucional, mas por conta da incidência de princípios constitucionais" (Cavalcante, 2015).

Evidentemente, cabe mencionar que a legislação traz alguns mecanismos para controlar os possíveis vícios advindos da prática da terceirização na administração pública. A Instrução Normativa n. 2 (2008) veda tanto a Administração quanto os servidores de praticarem atos de ingerência na administração da contratada, como o direcionamento de pessoas para trabalhar nas empresas terceirizadas vencedores do certame. O Decreto n. 7.203 (2010), que dispõe sobre a vedação do nepotismo no âmbito da administração pública federal, proíbe o familiar de agente público de prestar serviços no órgão ou entidade em que este exerça cargo em comissão ou função de confiança. Dessa maneira, os editais de licitação para a contratação de empresa prestadora de serviço terceirizado, devem estabelecer explicitamente, tal vedação (Decreto n. 7.203, 2010).

Contudo, embora os processos de seleção sirvam para escolher os candidatos mais qualificados e aptos com vistas a manter ou aumentar a eficiência na organização (Araújo, 2005) e Barbosa (2014) destacam que, no Brasil, os critérios de seleção baseados no mérito demonstram estar em permanente disputa com o nepotismo e os privilégios corporativos. Para a autora, expressões do tipo "apadrinhados" e "afilhados", dentre outras, são usadas frequentemente no meio organizacional e ilustram tanto as lógicas e as práticas de acesso quanto a promoção e o reconhecimento de cargos e funções.

Conforme destacado por Jensen e Stonecash (2004), os determinantes do sucesso da terceirização ainda não são conhecidos no setor público. Para muitos críticos, a terceirização não passa de mera intermediação de mão de obra. De acordo com Di Pietro (2009), os contratos têm sido celebrados sob a forma de prestação de 
serviços de modo a assegurar uma "aparente" legalidade, no entanto, para essa autora, tal prestação de serviço por parte da empresa contratada limita-se a fornecer mão de obra, mascarando a relação de emprego, que seria própria da administração pública, além de não proteger o interesse público e o benefício coletivo, pois, no processo de terceirização, o preço é um fator decisivo que pode permitir distorções, como simulação de comportamentos para preservar interesses individuais (Di Pietro, 2009).

Para Silva (2011), uma empresa terceirizada é a executora material, pois não lhe são transferidos poderes públicos. Assim, perante o usuário, seria a administração pública que apareceria como prestadora do serviço, o prestador do serviço sendo apenas o executor material para o contratante. Nesse sentido, cabe sempre considerar que o poder público será o sujeito diretamente relacionado com os usuários e, portanto, responsável direto pelos serviços (Mello, 2010).

Dessa maneira, quando uma empresa do setor privado torna-se responsável pelo recrutamento e seleção de funcionários do governo, a atividade coordenada entre o setor público e o privado indica que o segundo também deve suportar o dever de proteger os direitos constitucionais dos cidadãos. $\mathrm{O}$ texto do contrato oferece potencial para adaptar as parcerias público-privadas para que valores públicos estejam incluídos na prestação de serviços (Battaglio \& Ledvinka, 2009; Rosenbloom \& Piotrowski, 2005). Diante dessa perspectiva, um gestor público pode incluir requisitos como oportunidades iguais de acesso ao emprego. Como resultado, ao incorporar valores públicos nos contratos, estes se tornam parte do desempenho exigido da empresa do setor privado. Em outras palavras, por meio da inclusão de valores de direito público em contratos de terceirização, os gestores públicos podem estabelecer que tais valores sejam empregados para aferir o cumprimento do contrato da empresa privada, reforçando assim a prestação de contas ao público (Battaglio \& Ledvinka, 2009).

Devido às potenciais perdas de valores públicos, principalmente os valores do Direito Constitucional, que podem advir quando a responsabilidade é transferida do governo para uma empresa privada, Battaglio e Ledvinka (2009) destacam que os gestores públicos de contrato necessitam ter conhecimento em direito constitucional e contratual, entre outras regulaçóes, para projetar, monitorar e aplicar acordos de terceirização. Para os autores, o acompanhamento adequado dos contratos torna-se um elemento fundamental para garantir a legitimidade da decisão de terceirizar.

\section{METODOLOGIA}

Para atingir os objetivos propostos foi realizada uma pesquisa exploratória de abordagem qualitativa. Nessa pesquisa, foi empreendido um estudo de caso em uma instituição pública federal que atua em Minas Gerais. Esta instituição foi definida pela facilidade de acesso dos autores e contato com os responsáveis, além de a mesma apresentar um elevado número de funcionários terceirizados, estando entre as intuições públicas de mesma natureza que mais compromete seu orçamento com a terceirização, conforme dados extraídos do Portal da Transparência do Governo Federal (http://www.portaltransparencia.gov.br, recuperado em 20 de setembro de 2016).

Em relação à coleta de dados, destaca-se que foram utilizados dados primários e secundários. Os dados primários foram coletados por meio de entrevistas individuais semiestruturadas no segundo semestre de 2016. O roteiro da entrevista foi elaborado combinando perguntas abertas e fechadas, de modo a contemplar as principais características mencionadas na literatura de cada princípio que rege a administração pública brasileira e a permitir aos entrevistados que discorram sobre o tema proposto.

Os participantes da pesquisa foram selecionados após a realização de um levantamento da quantidade de funcionários que prestam serviço para a instituição pública federal há pelos menos três anos e que tinham sido contratados por duas ou mais empresas. Assim, buscou-se conseguir perfis de entrevistados que possuíssem vivência tanto em relação às empresas terceirizadas quanto em relação à organização pública, sendo selecionados para a entrevista prestadores de serviços nas área administrativa, de manutenção, de 
conservação, de limpeza e de vigilância. Foram entrevistados 14 funcionários terceirizados de empresas prestadoras de serviços para a administração pública, bem como com 2 gestores públicos desses serviços, ou seja, os fiscais dos contratos. Para garantir o sigilo e viabilizar a apresentação dos resultados, os sujeitos da pesquisa foram identificados como Entrevistado Terceirizado (ET, identificados de 1 a 14) ou Entrevistado Fiscal (EF, identificados de 1 a 2 ).

A coleta de dados secundários ocorreu pela obtenção de documentos institucionais da organização pública, entre os quais a relação dos funcionários terceirizados. Os editais e contratos celebrados entre a instituição pública federal e empresas terceirizadas que prestaram ou ainda prestam serviços para a referida instituição nos últimos seis anos (2010-2016) constituíram objeto de análise e foram obtidos pelo Portal de Compras do Governo Federal disponível no endereço eletrônico <http://www.comprasgovernamentais.gov.br>, recuperado em 25 setembro, 2016. Assim, foram analisados 41 contratos vinculados a 14 editais que tinham como finalidade a contratação de serviços diversos (auxiliar administrativo, secretário atendente, motorista, porteiro, copeira, encarregado de limpeza) e serviços especializados (vigilância desarmada).

Os dados foram analisados por meio da técnica de análise de conteúdo (Bardin, 2011), utilizando os princípios constitucionais como categorias prévias (legalidade, impessoalidade, moralidade, publicidade e eficiência). Destaca-se que a aplicabilidade dos princípios não limita-se à análise realizada neste estudo, mas os aspectos discutidos foram escolhidos de acordo com os objetivos do estudo.

\section{RESULTADOS E DISCUSSÃO}

Cada princípio foi analisado separadamente, contudo, a análise de um não necessariamente exclui aspectos que também podem estar atrelados aos demais.

Ao iniciar a análise dos editais e contratos da instituição pública federal, objeto deste estudo, verifica-se a diversidade dos serviços contratados, sendo que uma única empresa presta serviços variados. Estes serviços vão desde os relacionados às funções administrativas até aos serviços de limpeza e serviços gerais.

Embora a Instrução Normativa n. 2 (2008) não permita terceirizar atividades inerentes às categorias abarcadas pelo plano de cargos do órgão, com exceção para o caso de o cargo estar em extinção, a instituição pública justifica a necessidade da realização da contratação de serviços diversos no Termo de Referência dos editais de licitação alegando que não existem, no quadro da instituição, cargos suficientes destinados à realização das atividades, objeto da contratação (ECPE, 2010-2014a), o que já evidencia que a instituição pública terceiriza atividades que deveriam ser exercidas por servidores concursados.

Constatou-se que há terceirizados que exercem suas atividades nas áreas administrativas do órgão público que realizam atividades semelhantes às efetuadas por servidores efetivos:

[...] faço, eu acho, a mesma coisa... de alguns, sim! Acho que muitas coisas... muita coisa que eu faço... eu vejo que o servidor também faz (ET1).

É... auxiliar administrativo realiza funções que o servidor faz... pode ser que o servidor tenha mais atribuições, mas tem atividades que eles realizam a mesma coisa [...] (EF1).

Cavalcante (2015) afirma que "[...] à luz da legislação atual, é ilícita a terceirização, quando haja, nos quadros de pessoal do órgão ou entidade, cargo ou emprego que possa desempenhar a atribuição objeto da contratação". Infere-se, portanto, que a instituição pública vem adotando a terceirização para conseguir mão de obra para realização de suas atividades. Di Pietro (2009) já alegara que os contratos vêm sendo celebrados sob a forma de prestação de serviços, de modo a assegurar uma aparente legalidade, mas que na verdade limitase a fornecer mão de obra, mascarando a relação de emprego.

Conforme destacado por Pazzaglini (2008) e Meirelles (2009), na administração pública não há liberdade para o exercício de vontades pessoais, visto que é permitido fazer apenas o que a lei autoriza. Entretanto, práticas de ingerência no caso analisado são evidenciadas no processo de terceirização, na medida em que, 
de acordo com a Instrução Normativa n. 2 (2008), não é permitido aos agentes públicos direcionar a contratação de pessoas para trabalhar nas empresas contratadas. Porém, o que foi observado é que ocorre o direcionamento das contratações, bem como promoções de cargos por definição de servidor. Conforme a ET10, "quem me indicou foi a servidora [...]". Assim, percebe-se indícios de interferência dos servidores da instituição pública quando estes indicam pessoas para trabalharem nas empresas terceirizadas.

Mello (2010) destaca que o princípio da legalidade contrapõe-se às tendências personalistas. Dessa forma, agentes públicos não podem direcionar pessoas para trabalhar nas empresas terceirizadas, assim como as solicitações de serviços, reclamações ou cobranças relacionadas aos funcionários terceirizados devem ser direcionadas ao preposto para não caracterizar atos de ingerência (Instrução Normativa n. 2, 2008). Contudo, as decisóes e responsabilidades que caberiam às empresas terceirizadas e executadas pelos prepostos, são, por vezes, realizadas informalmente por agentes públicos, o que leva a mascarar o vínculo de emprego e sugere que a figura dos prepostos seja necessária apenas para viabilizar a terceirização. Nesse sentido, Di Pietro (2009) relata que, no que se refere à administração pública, mascarar a relação de emprego não protege o interesse público e o benefício coletivo, pois pode permitir distorções para contemplar interesses individuais.

A vedação à criação de vínculo entre os funcionários terceirizados e a instituição pública é descrita nos editais e nos contratos, na medida em que é destacado que os empregados da empresa terceirizada "não manterão nenhum vínculo empregatício com a contratante" (ECPE, 2010-2014a, 2010-2014b). Freitas e Maldonado (2013) destacam que a inexistência de vínculo entre os funcionários das empresas terceirizadas e a instituição contratante é algo apenas formal. Conforme constatado nas entrevistas com os terceirizados, todos passaram por duas ou mais empresas num período de apenas seis anos. A ET12 chegou a passar por quatro empresas nesse período, o que demonstra que apenas as empresas passam pela instituição pública, mas as pessoas continuam. Além disso, pôde ser constatado que existem funcionários que prestam serviço para a instituição pública estudada há cerca de 25 anos.

Assim, a não geração de vínculo entre os funcionários terceirizados e a instituição pública, que é explícita nos editais e nos contratos, na prática, se mostra uma premissa falsa, pois fica evidente que o que se terceiriza são as pessoas e não os postos de serviços, os quais são objeto apenas durante o processo de licitação. Isso reflete no vínculo subjetivo existente, que se torna objetivo através da continuidade das mesmas pessoas a cada troca de empresa, uma vez que pode ser observado nas entrevistas que a instituição pública realiza pedidos informais às empresas que ganham as licitações para manter os mesmos funcionários, conforme a EF1. Situações como essa, de certa forma, caracterizam a existência de direcionamento de pessoas para trabalharem nas empresas contratadas, o que não é permitido à Administração ou aos servidores, conforme Instrução Normativa n. 2 (2008), à qual os editais e contratos analisados vinculam-se.

Práticas de direcionamento indireto por meio de empresas terceirizadas representam não observância de princípio de legalidade pela instituição pública pesquisada. Isso indica que a empresa terceirizada está transferindo, de forma voluntária ou não, a responsabilidade de suas obrigações para terceiros, o que lhe é vedado por força legal e contratual (ECPE, 2010-2014a, 2010-2014b), sem o consentimento da contratante. No entanto, com a transferência de responsabilidade para a própria instituição pública, a autorização já está implícita, mesmo sendo ilegal.

Embora Lourenço (2015) destaque a falta de segurança dos funcionários terceirizados, que desencadeia uma falta de perspectiva funcional de estabilidade dos mesmos, o caso analisado demonstra que a instituição pública, ao interferir para mantê-los nos postos de trabalho, lhes oferece a proteção da estabilidade mascarada que, ao ter essa atitude, acaba evidenciado e fortalecendo o vínculo entre esta e os funcionários terceirizados. Além disso, há caracterização de ações em desacordo com leis, normas e regulamentos no processo de terceirização no caso estudado.

Uma administração pública flexível não exclui a necessidade da seleção por mérito, ao contrário, a profissionalização é imprescindível para buscar a legitimação organizacional (Pimenta, 1998). Nesse sentido, 
o princípio da impessoalidade na execução do serviço terceirizado foi analisado principalmente no que se refere à seleção e formação do quadro de funcionários.

Conforme Paulo e Alexandrino (2015), a impessoalidade deriva da igualdade no tratamento como meio de evitar discriminações ou benefícios. Silva e Souza (2004) destacam que existem riscos de utilizar a terceirização no setor público para fins de apadrinhamento. No caso analisado, constata-se que o apadrinhamento é algo necessário para quem pleiteia uma vaga como funcionário terceirizado na instituição pública. Verifica-se que o princípio da impessoalidade não é observado pelas empresas terceirizadas, na medida em que não apenas as indicações ocorrem, mas a prática de beneficiar quem é parente pode ser constatada quando perguntado aos entrevistados se existem funcionários terceirizados com parentesco na empresa para a qual prestam serviço, quase a totalidade afirmou que sim. Os próprios fiscais de contrato também relataram que existem indicações e relações de parentesco:

[...] é muito complicado... tipo... tem quase que a família inteira trabalhando pela terceirizada, entendeu... olha, entrou fulano que indicou o irmão, que indicou a irmã, que indicou a cunhada que indicou o marido [...] (EF1).

Para Barbosa (2014), as expressões "Qi” (“quem indica”), “apadrinhados”, dentre outras, ilustram lógicas de acesso ao emprego contrárias ao mérito. Costa (2007) também demonstra em seu estudo que a contratação entre os terceirizados e a empresa de terceirização se dá normalmente por indicação de algum conhecido, amigo ou parente, o que corrobora com os achados deste estudo. Nesse sentido, os relatos dos entrevistados evidenciam que as indicações são um meio de ingresso bastante praticado pelas empresas terceirizadas, as quais prestam serviço para a instituição pública pesquisada.

$\mathrm{Na}$ análise dos editais e contratos (ECPE, 2010-2014a, 2010-2014b) não foi constatada vedação em relação ao direcionamento de funcionários terceirizados por prepostos e por funcionários terceirizados. Porém, a Instrução Normativa n. 2 (2008) determina que é o gestor do contrato que exerce a função de fiscalização e acompanhamento da execução dos serviços contratados e que deve informar à instituição pública sobre eventuais vícios na prestação dos serviços pela contratada, bem como propor solução para regularização. Dessa forma, pode-se inferir que os vícios decorridos das indicações, apadrinhamento e do nepotismo velado poderiam ser corrigidos se solicitados pelos fiscais de contratos, tendo em vista o interesse público envolvido.

Evidenciou-se que duas entrevistadas terceirizadas possuem parentes na instituição pesquisada, embora não fosse possível comprovar a influência das pessoas com as quais possuem parentescos na seleção. Entretanto, caso da ET10, constatou-se que ela foi indicada por uma servidora da instituição pública que exerce um cargo na alta administração do órgão. Dessa forma, as indicações por parte de servidores públicos acontecem mesmo sendo vedado pela Instrução Normativa n. 2 (2008), à qual os editais e contratos analisados estão vinculados . Os "aquários" vão sendo construídos, conforme denominado pelo EF2, ora constituídos pelos prepostos e funcionários terceirizados, ora por agentes públicos. De acordo com EF2:

[...] infelizmente tem interferência, tem ingerência, tem relações de amizade... existe o aquário... cada um vai escolher seu peixe, né... causa muito transtorno, é muito complicado [...] (EF2).

O Decreto n. 7.203 (2010) dispõe sobre a vedação do nepotismo no âmbito da administração pública federal e veda ao familiar de agente público que presta serviços no órgão ou entidade em que este exerça cargo em comissão ou função de confiança. Mesmo sendo uma medida de combate ao nepotismo nos processos de terceirização no setor público, o decreto contém limitações na medida em que caracteriza como nepotismo apenas o caso de o funcionário terceirizado ser familiar de agente público que exerça cargo em comissão ou função de confiança. Embora a caracterização de nepotismo seja mais abrangente tendo em vista que Pazzaglini (2008) o entende como a concessão por agentes públicos de favores, ajudas e privilégios de cunho público a seus parentes, amigos e correligionários. Nesse sentido, é possível inferir que quando agentes 
públicos interferem direcionando funcionários para atuarem nas empresas terceirizadas, estão contribuindo com a prática de nepotismo no setor público.

Embora os entrevistados que possuem parentesco com servidores tenham ressaltado que nenhuma das pessoas com as quais possui parentesco exercem função, ou seja, cargo de direção, chefia ou assessoramento, infere-se que ao realizar tal consideração, acreditam que não estão em situação de nepotismo. Entretanto, é possível dizer que causa estranheza agentes públicos indicarem ou direcionarem pessoas para trabalharem nas empresas terceirizadas, o que é vedado, conforme Instrução Normativa n. 2 (2008), assim como levanta questionamentos sobre funcionários terceirizados que possuem parentesco com servidores onde atuam, principalmente quando constatado que a forma dominante de ingresso nas empresas terceirizadas ocorre por meio de indicações, bem como tendo em vista a inexistência de processos isonômicos de seleção, o que acarreta a valorização das relações pessoais em detrimento do mérito. Assim, desprovidos de processos isonômicos (Mello, 2010; Paulo \& Alexandrino, 2015), é possível afirmar que as situações evidenciam o desrespeito ao princípio da impessoalidade.

Nohara (2014) destaca que os resquícios do paternalismo nos ambientes públicos dificultam a efetivação tanto da impessoalidade como da moralidade no contexto brasileiro. As indicações por parte de prepostos, conforme aferido nas entrevistas, uma vez que muitos empregam a família inteira nas empresas terceirizadas, demonstra inobservância do princípio da moralidade. Mesmo não sendo ilícito do ponto de vista da legalidade, evidencia ser imoral, pois segundo Di Pietro (2010a), mesmo em consonância com a lei, haverá ofensa ao princípio da moralidade quando o comportamento do administrado que se relaciona com a administração pública juridicamente afrontar as regras da boa administração, não apenas na constatação da atuação desses agentes na utilização de seus cargos para benefício de seus familiares e amigos, como também na utilização de seus cargos de maneira incompatível com relação ao trato daquilo que é público.

Para Nohara (2014), o princípio da moralidade tem como finalidade coibir tanto o nepotismo direto como também o indireto, manifestado em indicações cruzadas, triangulares ou de reciprocidades. Dessa maneira, mesmo que os casos encontrados neste estudo não caracterizem claro nepotismo e mesmo que as contratações venham sendo realizadas dentro de uma suposta legalidade, sob a ótica da moralidade não se confirma, pois nem tudo que é legal é necessariamente moral (Nohara, 2014).

Foi perguntado aos fiscais de contrato se existe algum tipo de controle quanto à indicação, tanto por agentes públicos quanto por funcionários terceirizados, de pessoas para trabalharem nas empresas terceirizadas, as respostas indicam desconhecimento da própria legislação. De acordo com a EF1, a legislação proíbe parentesco entre funcionário terceirizado e servidor público, mas afirmou que ela poderia indicar algum familiar, mas destacou que "hoje não indico", em virtude de não ser ético, mas suas palavras remetem à ideia de que já tenha realizado indicações, além de ser possível constatar desconhecimento da mesma em relação à Instrução Normativa n. 2 (2008) que veda o direcionamento de funcionários terceirizados por parte de servidores federais. Ao contrário da EF1, o EF2 demonstra conhecimento em relação à vedação de indicações, de funcionários terceirizados por agentes públicos, mas mesmo que seja proibido, o mesmo afirma que as indicações ocorrem no formato de sugestões. Entretanto, o EF2, ao destacar que não há problema na realização de indicações por parte dos terceirizados, desconsidera os aspectos éticos que podem vir a ser afrontados com as indicações, ou seja, assim como há afrontamento ao princípio da moralidade quando agentes públicos direcionam e fazem "sugestões" de funcionários para trabalhar em empresas terceirizadas, também é imoral as indicações realizadas por prepostos e funcionários terceirizados em relação a familiares e amigos, visto que cria e reforça os vícios na administração pública.

O princípio da moralidade é um instrumento necessário para a defesa do ideário republicano, o qual é avesso à ideia de confusão entre patrimônio público e a coisa privada (Nohara, 2014). As práticas advindas com o processo de terceirização, ao serem utilizadas para favorecimento próprio ou de terceiros, sugerem uso indevido desse mecanismo para alcance de interesse privados. 
A publicidade é analisada, principalmente, sob a ótica da importância da divulgação das vagas de emprego como mecanismo de tornar transparente a forma de acesso nas empresas terceirizadas que prestam serviços no setor público, como também meio de controle de práticas que privilegiam o interesse privado em detrimento do interesse público. Para Mello (2010), o princípio da publicidade busca manter a plena transparência do comportamento administrativo como meio de não haver ocultamento dos assuntos de interesse coletivo. Nesse sentido, entende-se que a divulgação das vagas de emprego constitui um assunto de interesse coletivo, na medida em que o trabalho é um direito social previsto na Constituição Federal brasileira (1988).

É possível observar, tanto nas entrevistas com os fiscais quanto com os funcionários terceirizados, que não existe divulgação em meio formal das vagas de emprego, assim como na análise dos editais e contratos não se verifica a exigência de divulgação, embora o fato de prestarem um serviço público, seja fator considerável para que as empresas terceirizadas estejam sujeitas à transparência. Constatou-se que a forma de divulgação das vagas de emprego ocorre informalmente, por meio do chamado "boca a boca". Assim,

[...] quem fica sabendo é só mais os amigos e alguém que, por sorte, passa aqui e deixa currículo (ET3).

A publicidade é condição necessária à transparência (Pazzaglini, 2008), por isso as informações de interesse geral devem ser disponibilizadas como meio para criar oportunidades iguais. No caso estudado, há relatos que sobre a não oferta de oportunidades:

[...] ela não coloca, não publica... estamos contratando, traga seu currículo... tá... quem passou por aqui e deixou um currículo, tá... mas o quê que acontece muito... olha, fulano indicou beltrano... então as vezes vem dois, três, quatro indicados, entendeu... então você sabe que a possibilidade de ser contratado um indicado é muito maior, entendeu (EF1).

A divulgação formal das vagas é deficitária, sendo praticamente inexistente, assim como a divulgação dos pré-requisitos para preenchimento das mesmas também são, pois a maioria dos entrevistados terceirizados afirma que não existe divulgação dos pré-requisitos, o que pode ser observado na fala de EF1:

Nunca vi também... como eles não divulgam nem a vaga... nem o que precisa [...] (EF1).

Dessa forma, o discurso do EF1 demonstra conformidade com a dos entrevistados terceirizados. $\mathrm{Na}$ fala da ET1 é possível verificar que, via de regra, as indicações são utilizadas como mecanismo para preencher as vagas e a divulgação das mesmas e dos pré-requisitos ficam restritos aos que "tem acesso" ou aos que tiveram "a sorte".

As indicações, implícita ou explicitamente, ganham destaque em detrimento de processos formais e transparentes, o que pode colaborar para a viabilização de prática de favorecimento e direcionamento, por parte dos agentes públicos, de pessoas para trabalhar nas empresas terceirizadas, bem como a prática de nepotismo velado, visto que este pode ser entendido como a concessão de favores, ajudas e privilégios por agentes públicos, não apenas a seus parentes, mas também aos amigos (Pazzaglini, 2008).

A não divulgação e transparência das vagas refletem na baixa competição, pois constatou-se que o número de candidatos é baixo, em torno de cinco, ou inexistente, conforme constatado nas entrevistas com os indivíduos ET1, ET3, ET8, ET13, que responderam que não havia mais candidatos quando realizaram a seleção.

Constata-se que o "boca a boca" é o mecanismo institucionalizado pelas empresas terceirizadas para divulgação das vagas para preenchimento dos postos de trabalho. Dessa forma, por não haver divulgação das vagas de emprego em meios formais, o princípio da publicidade não está presente na prática de terceirização sob a ótica analisada, embora seja um mecanismo fundamental para coibir práticas indesejáveis no setor público, como o apadrinhamento e fazer com que os interesses privados não se sobressaiam, visto que o mesmo visa conferir certeza às condutas no setor público (Pazzaglini, 2008). Pelas práticas que atualmente são realizadas, a não divulgação é desejável, pois na medida em que os processos se tornarem públicos, a concorrência pelas vagas poderia se tornar maior. Como atualmente conseguem trabalho os que tem "a sorte" 
ou tem o fator "Qi”, tornar público e transparente o processo de recrutamento, seleção e divulgação das vagas de emprego seria desmontar a lógica de uma administração patrimonialista vigente, pois demonstra claros resquícios paternalistas (Barbosa, 2014; Nohara, 2014).

Costa (1994) destaca a geração de emprego como um dos aspectos positivos no processo de terceirização. No setor público, a geração de postos de trabalho com a terceirização é dada pelo Estado, por isso, deve ser levada em conta a observância da publicidade, bem como dos demais princípios para oportunizar admissão aos desprovidos "de acesso".

Nohara (2014) destaca que a publicidade permite aos cidadãos terem conhecimento das ações realizadas no espaço público. Entretanto, observa-se que a falta de transparência na divulgação de critérios para preenchimento dos postos de trabalho gera incerteza acerca dos meios adotados pelas empresas terceirizadas. Dessa maneira, é possível dizer que nas relações contratuais entre instituição pública e empresas terceirizadas constituiu-se um ambiente propício a práticas oportunistas, esta evidenciada pela busca de interesses individuais, atrelados a lacunas contratuais como a não exigência de transparência e publicidade, ou seja, da observância do princípio da publicidade colabora para o não atendimento do interesse público e da promoção do bem comum.

O princípio da eficiência é dirigido para a busca de resultados de modo rápido e preciso, visando à satisfação do interesse público (Pazzaglini, 2008). Para Pimenta (1998), uma administração pública flexível e focada em resultados necessita de recursos humanos qualificados para desempenhar as funções com eficiência e qualidade.

A seleção visa escolher funcionários qualificados e aptos (Araújo, 2005). Experiência e escolaridade foram fatores identificados nos editais e contratos (ECPE, 2010-2014a, 2010-2014b) como critério para a execução das funções, com exceção do cargo de vigilante, contudo, não é o que vem sendo praticado. Em relação à experiência, a mesma não vem sendo tratada como exigência para ingresso, mas apenas considerada como um fator potencialmente aplicável, constatado mesmo nas falas de quem afirmou haver exigência de experiência.

[...] precisava sim, de experiência assim... que tivesse trabalhado já na área de auxiliar administrativo, mas eu não tinha [...] (ET1).

Outro aspecto identificado diz respeito à qualificação/habilitação dos funcionários terceirizados. Conforme editais e contratos analisados, as empresas devem manter os funcionários com a qualificação exigida para executar os serviços contratados (ECPE, 2010-2014a, 2010-2014b). Entretanto, também foi constatado na pesquisa um caso de incompatibilidade entre o nível de escolaridade exigido e o nível de escolaridade declarado. No caso de auxiliar administrativo é exigido, além da experiência comprovada de um ano, a apresentação de certificado de ensino médio completo (ECPE, 2010-2014a). O ET9 declarou, na entrevista, não possuir ensino médio completo, fazendo com que, perante as exigências dos editais e contratos, não estivesse habilitado para a função de auxiliar administrativo. Embora seja com base no processo de seleção que se escolhe funcionários qualificados com vistas a manter ou aumentar a eficiência (Araújo, 2005), isso não demonstra constituir preocupação quando empresas terceirizadas assumem serviços públicos, na medida em que as mesmas não acatam as determinações dos editais e contratos.

Reduzir custos é frequentemente relacionado à eficiência (Motta, 2007), bem como fator predominantemente destacado para se utilizar a terceirização, embora se mostre questionável quando as empresas terceiras não cumprem com as exigências contratuais, oferecem funcionários com baixa qualificação (Costa, 2007; Souza \& Silva, 2004) e não investem em capacitação e qualificação de seus funcionários (Magalhães, Carvalho e Saraiva, 2011).

Nos editais e contratos ECPE 01/2010 e 02/2010, o treinamento/reciclagem de pessoal eram descritos como insumos e nos demais, os valores gastos pelas empresas terceirizadas e pagos pela instituição pública passaram a compor as despesas administrativas (ECPE, 2010-2014a, 2010-2014b). Embora com denominações diferentes, o fato é que a instituição pública tem um custo com treinamento/reciclagem dos 
funcionários terceirizados. Ao constar nos editais e contratos tal exigência, infere-se que são aspectos que visam buscar eficiência. Dessa maneira, cabe à contratada providenciar treinamento para seus funcionários conforme previsto na relação de obrigações da mesma. Verificou-se pelos relatos que ocorrem treinamentos realizados por servidores ou pelos funcionários terceirizados que já executam a função. Conforme EF1:

[...] Normalmente, eles são treinados nos setores. [...] é os próprios servidores que fazem o treinamento, tá" (EF1).

Tal prática é confirmada pela maioria dos entrevistados (ET1; ET3; ET4; ET7; ET9; ET10; ET11; ET12; ET13; ET14) quando destacaram que os servidores públicos são responsáveis ou corresponsáveis pelo treinamento ou orientações, como muitas das vezes preferem chamar.

Conforme Di Pietro (2010a) e Paulo e Alexandrino (2015), o princípio da eficiência visa alcançar o melhor resultado diante do recurso utilizado. Embora sob diversas denominações, como treinamentos, orientações ou ensinamentos, que caberiam as empresas realizarem, as mesmas não os fazem. A falta de treinamento dos terceirizados faz com que as empresas terceirizadas aumentem seu lucro gerando um efeito inverso para a instituição pública, pois os treinamentos, ao serem realizados pelos próprios servidores, acabam tornandose dispendiosos para a instituição pública, ao pagar o treinamento que não é realizado de maneira formal. Dessa maneira, a instituição pública paga por algo que não é realizado, ou seja, o que se gasta com serviços terceirizados não revela benefícios plausíveis (Silva \& Souza, 2004), o que não corresponde a eficiência.

Para Motta (2007), a terceirização de serviços públicos visa à diminuição de gasto, bem como atingir maior eficiência. Entretanto, a efetividade desse mecanismo é questionável, na medida em que observa a interferência indireta da contratante para que o serviço seja executado.

Para Di Pietro (2010a) e Paulo e Alexandrino (2015), o princípio da eficiência deve ser aspirado por meio de uma atuação com qualidade, procurando obter um padrão de excelência no desempenho das atribuições. Embora uma seleção criteriosa possa resultar em desempenho adequado dos funcionários, o que não evidenciou-se no caso analisado, deve também ser atestada, posteriormente, pela avaliação de desempenho (Araújo, 2005). Para Silva e Souza (2004), o funcionário terceirizado que presta serviço na administração pública deve ser avaliado na consecução de suas atividades.

Fatos da não existência de avaliação de desempenho dos funcionários, assim como não avaliação formal do serviço executado, foram relatados. Assim, o funcionário terceirizado não precisa apresentar resultado ótimo para se manter na função. Tal fato pode acarretar a permanência de funcionários que não apresentam bons resultados até porque

[...] mandar embora é a última instância... só é mandado embora daqui quem quiser ir embora... porque tem que ser muito ruim pra ser mandado embora [...] (EF2).

As contratações baseadas nas indicações e no apadrinhamento não levam em consideração os princípios da impessoalidade e moralidade e, consequentemente, comprometem o princípio da eficiência, na medida em que mesmo o funcionário terceirizado não sendo produtivo ele é mantido na função, em virtude da proteção e do apadrinhamento. Assim, ao não observar um princípio, acaba gerando um efeito cascata no sentido de provocar a inobservância dos demais.

Ao desconsiderarem as implicações negativas que podem advir com as práticas de terceirização na administração pública, ou melhor, a não observância dos princípios que a regem pode desencadear em práticas de favorecimentos dentre outros, alimentando os vícios no trato da coisa pública, além de negligenciar o caráter público dos serviços prestados como foi evidenciado. 
Quadro 1 - Categorias e principais aspectos encontrados na execução dos serviços terceirizados

\begin{tabular}{|c|c|c|}
\hline Categoria & Aferição & $\begin{array}{l}\text { Principais aspectos encontrados na prática } \\
\text { (Execução dos serviços) }\end{array}$ \\
\hline Legalidade & $\begin{array}{l}\text { Terceirização lícita Vedação à } \\
\text { subordinação e direcionamento Ausência } \\
\text { de Pessoalidade Relaçôes impessoais } \\
\text { Cumprimento do contrato Atuação } \\
\text { conforme a lei/normas }\end{array}$ & $\begin{array}{l}\text { Caracterização de Terceirização ilícita Prática } \\
\text { de ingerência Presença de pessoalidade } \\
\text { Relaçôes paternalistas Violação das } \\
\text { exigências contratuais Inobservância de } \\
\text { normas }\end{array}$ \\
\hline Impessoalidade & $\begin{array}{l}\text { Isonomia Igualdade de oportunidade } \\
\text { Vedação ao Nepotismo Ausência de } \\
\text { pessoalidade Relações impessoais }\end{array}$ & $\begin{array}{l}\text { Favorecimentos Benéficas Caracterização de } \\
\text { Nepotismo "Qi", Apadrinhamento Relações } \\
\text { paternalistas }\end{array}$ \\
\hline Moralidade & $\begin{array}{l}\text { Comportamento ético, boa conduta } \\
\text { Respeito e cumprimento das obrigaçóes } \\
\text { contratuais e legais Respeito às regras de } \\
\text { boa administração Interesse público }\end{array}$ & $\begin{array}{l}\text { Presença de comportamento oportunista } \\
\text { Desrespeito às obrigações contratuais e } \\
\text { legais condutas incompativeis com regras de } \\
\text { boa administração Interesse privado }\end{array}$ \\
\hline Publicidade & $\begin{array}{l}\text { Transparência / Meios e abrangência Nível } \\
\text { de facilidade de acesso do } \\
\text { público Divulgação de vagas de } \\
\text { emprego Transparência nos critérios de } \\
\text { acesso }\end{array}$ & $\begin{array}{l}\text { Processos baseados no "boca a boca" / meios } \\
\text { informais e abrangência limitada } \\
\text { Dificuldade de acesso pela não utilização de } \\
\text { mecanismos formais de divulgação } \\
\text { Divulgação deficitária e predominantemente } \\
\text { informal. Falta de transparência nos critérios } \\
\text { de acesso }\end{array}$ \\
\hline Eficiência & $\begin{array}{l}\text { Cumprimento dos requisitos de } \\
\text { qualificação profissional/Per fil de acordo } \\
\text { com editais e contratos } \\
\text { Treinamento/Capacitação/ Reciclagem } \\
\text { Acompanhamento e Avaliação de } \\
\text { desempenho }\end{array}$ & $\begin{array}{l}\text { Contratações em desacordo com Perfil } \\
\text { descrito no editais e contratos Preparação } \\
\text { deficitária dos } \\
\text { funcionários Acompanhamento e Avaliação } \\
\text { informal baseadas em Reclamações }\end{array}$ \\
\hline
\end{tabular}

O quadro acima demonstra de maneira resumida que os aspectos encontrados na literatura, nos editais, contratos e normas vinculadas aos mesmos, quando contrastados com a prática, demonstram que os valores públicos são perdidos na prestação do serviço por empresas terceirizadas.

\section{CONSIDERAÇÕES FINAIS}

Este estudo analisou editais, contratos e a prestação de serviços terceirizados em uma instituição pública federal localizada em Minas Gerais, investigando a aplicação dos princípios da administração pública brasileira constituídos pela legalidade, impessoalidade, moralidade, publicidade e eficiência.

$\mathrm{Na}$ legalidade os agentes públicos deveriam observar o estabelecido nos editais e contratos, uma vez que na administração pública as atuações devem ser exercidas em conformidade com a lei (Mello, 2010). Contudo, pôde ser observado que várias ações foram descritas de maneira a ilustrar que esse princípio não vem sendo efetivamente praticado pela instituição pública, no que se refere à terceirização. À medida que os funcionários e empresas terceirizadas violam o que está estabelecido em editais e contratos públicos ou transfere responsabilidade para a administração pública, constitui contrariedade ao que é legal.

A impessoalidade, no caso analisado, não vem sendo obedecida, pois a terceirização tornou-se um elemento que viabiliza a consecução de interesses privados ao invés de satisfazer os interesses públicos. Assim, constatase que esse princípio não é observado pelas empresas terceirizadas, além de ser esquecido pela instituição pública que, ao contrário, é renegado aos vícios de um modelo de administração pública patrimonialista, na medida em que as práticas de favorecimento, concessão de privilégios, apadrinhamento, entre outros, demonstraram estar fortemente estabelecidas. 
A moralidade é perdida no caso analisado, na medida em que há presença de comportamentos oportunistas em detrimento de condutas éticas. Observa-se comportamentos em desacordo com as regras de boa administração, com os princípios de justiça e de equidade, bem como com a ideia comum de honestidade.

Os aspectos encontrados na prática da terceirização na instituição pública denotam a inobservância do princípio da publicidade, uma vez que a negação desse princípio apresenta-se por meio de práticas obscuras, amadoras e não transparentes diante da sociedade. As empresas terceirizadas prestadoras de serviços públicos devem estar sujeitas à transparência, tanto em relação aos seus empregados, instituição pública ou em relação aos cidadãos, uma vez que recebem recursos provenientes da contribuição dos últimos. A transparência deve permear seus atos e ser exigida pela instituição pública, assim como as organizações públicas devem fiscalizar e cultivar sua efetivação, além de exigir a observância da publicidade.

O princípio da eficiência idealizado numa perspectiva gerencial vislumbra uma administração enxuta, contudo, a terceirização vem servindo para inchar a máquina pública, visto que sua prática, na instituição pesquisada, faz com que a mesma se torne a segunda prefeitura dos municípios em que atua, na medida em serve de "cabide" de emprego para parentes, amigos e conhecidos de prepostos e até mesmo de servidores públicos.

Assim, terceirização no serviço público não se traduz em benefícios plausíveis, além de não proteger o interesse público, pois afronta os valores públicos. Com base na discussão e nos dados empíricos, é possível perceber que a terceirização abre caminhos para práticas como o clientelismo, apadrinhamento, favorecimentos, seleção inadequada de funcionários, os quais podem levar à perda de qualidade dos serviços prestados, pois as contratadas não investem em qualificação e treinamento dos funcionários. Outros aspectos podem ser elencados, como a existência de vínculos com a empresa contratante que ocorre de forma mascarada, fazendo com que essa prática se revele como mera intermediação de mão de obra. Assim, as empresas terceirizadas fornecem mão de obra para a administração pública e, portanto, são responsáveis pelo recrutamento e seleção de funcionários que prestarão serviços públicos (Battaglio \& Ledvinka, 2009).

Percebeu-se que as empresas terceirizadas não se mostram preocupadas com o alcance do interesse público, mas apenas visam lucro, na medida em que não se comprometem a fornecer o serviço de acordo com o que se propuseram a entregar. A falta de opção de contratações via concurso público leva a administração pública a utilizar desse mecanismo para conseguir funcionários, porém, ao aderir a esse mecanismo, ocorre perda de valores públicos e afloramento dos vícios da administração pública brasileira.

Entretanto, a partir das exigências estabelecidas nos editais e contratos, é um começo para tentar inibir práticas indesejáveis nas atividades de natureza pública. Estes são os instrumentos, atrelados a uma fiscalização efetiva, que têm potencial para que os valores públicos estejam presentes na prestação de serviços terceirizados (Battaglio \& Ledvinka, 2009; Rosenbloom \& Piotrowski, 2005).

No Brasil, a atual crise financeira e política fornece um cenário em que os governos pensem em introduzir reformas no sentido de reduzir o tamanho do setor público (Alonso, Clifton \& Díaz-Fuentes, 2015), o que reforça a necessidade de uma regulamentação dessa prática não apenas no setor privado, mas também no setor público. Nesse sentido, esta pesquisa buscou contribuir para melhorar as práticas de terceirização no setor público brasileiro, bem como trazer discussões sobre o tema, uma vez que as restriçóes impostas por um cenário de austeridade e enxugamento do Estado fazem com que esse mecanismo seja expandido.

Acredita-se que a ação das empresas, dos dirigentes, dos empregados e de todos os que exercem atividades em nome de órgãos públicos deveria ser norteada pelos valores descritos na Constituição ou, no mínimo, não contrariá-los, constituindo obrigação dos responsáveis por contratações de empregados, estagiários e prestadores de serviços em geral fazer constar nos respectivos contratos a sua plena observância.

Devido às limitações deste estudo e aos aspectos inerentes à utilização de pesquisa qualitativa, sugerese que pesquisas futuras abordem a natureza quantitativa em relação à efetividade de redução de custos na administração pública brasileira pela utilização da terceirização. Sugere-se também uma análise específica sobre os custos de transação. Levantamentos futuros também poderão analisar, de maneira quantitativa, qual 
o percentual de indicações e relação com graus de parentesco, além de expandir a análise para um número maior de instituições públicas e suprir lacunas deixadas neste estudo.

\section{REFERÊNCIAS}

Alexandrino, M., \& Paulo, V. (2012). Direito Administrativo descomplicado (20a ed.). Rio de Janeiro: Forense.

Alonso, J. M., Clifton, J., \& Díaz-Fuentes, D. Did new public management matter? An empirical analysis of the outsourcing and decentralization effects on public sector size. Public Management Review, 17(5), 643-660.

Araújo, A. P. (2005). Eficiência dos processos seletivos nas contratações das empresas privadas de Pirassununga. Anuário, 160-167. Recuperado de: http://repositorio.pgsskroton.com.br/bitstream/123456789/927/1/artigo \%2020.pdf

Barbosa, L. (2014). Meritocracia e sociedade brasileira. Revista de Administração de Empresas, 54 (1), 80-85.

Bardin, L. (2011) Análise de conteúdo. São Paulo: Edições 70.

Battaglio, R. P. J., \& Ledvinka, C. B. (2009). Privatizing human resources in the public sector: legal challenges to outsourcing the human resource function. Review of Public Personnel Administration, 29(3), p. 293-307.

Carvalho, J. S. F. (2009). Manual de Direito Administrativo (21a ed.). Rio de Janeiro: Lumen Juris.

Carvalho, J. S. F. (2010). Interesse público: verdades e sofismas. IN M. S. Z., Di Pietro, \& C. V. A, Ribeiro. (Coords.). Supremacia do interesse público e outros temas relevantes do direito administrativo (pp. 67-84). São Paulo: Atlas.

Cavalcante, J. T. F. (2015). Terceirização na administração pública e princípio constitucional do concurso público: considerações sobre o PL no 4.330, de 2004. Brasília, DF: Núcleo de Estudos e Pesquisas/CONLEG/Senado.

Constituição da República Federativa do Brasil de 1988. (1988) Brasília, DF: Senado Federal.

Costa, M. S. (1994) Terceirização/parceria e suas implicações no âmbito jurídico-sindical. Revista de Administração de Empresas, 34(1), 6-11.

Costa, S. G. (2007). O pai que não é o patrão: vivências de sujeitos terceirizados no Ministério Público do Estado do Rio Grande do Sul. Organizações \& Sociedade, 14(42), 97-113.

Decreto ${ }^{\circ}$ 7.203, de 4 de junho de 2010. (2010). Dispõe sobre a vedação do nepotismo no âmbito da administração pública federal. Diário Oficial da União, Brasília, DF: Poder Executivo.

Di Pietro, M. S. Z. (2010a). Direito Administrativo (23a ed.). São Paulo: Atlas.

Di Pietro, M. S. Z. (2010b). O princípio da supremacia do interesse público: sobrevivência diante dos ideais do neoliberalismo. IN M. S. Z., Di Pietro, \& C. V. A, Ribeiro. (Coords.). Supremacia do interesse público e outros temas relevantes do direito administrativo (pp. 85-102). São Paulo: Atlas.

Di Pietro, M. S. Z. (2009). Parcerias na administração pública (7a ed.). São Paulo: Atlas.

Freitas, M., \& Maldonado, J. M. S. V. (2013). O pregão eletrônico e as contratações de serviços contínuos. Revista de Administração Pública, 47(5), 1265-281.

Instrução Normativa n ${ }^{\circ}$, de 30 de abril de 2008. (2008). Dispõe sobre regras e diretrizes para a contratação de serviços, continuados ou não. Diário Oficial da União, Brasília, DF: Poder Executivo.

Jensen, P. H., \& Stonecash, R. E. (2004). The efficiency of public sector outsourcing contracts: a literature review. Melbourne Institute Working Paper, 29, 1-32.

Lei no 8.666, de 21 de junho de 1993. (1993). Regulamenta o art. 37, inciso XXI, da Constituição Federal, institui normas para licitações e contratos da Administração Pública e dá outras providências. Diário Oficial [da] República Federativa do Brasil, Brasília, DF: Poder Executivo.

Lourenço, E. A. S. (2015) Terceirização: a derruição de direitos e a destruição da saúde dos trabalhadores. Serviço Social \& Sociedade, (123), 447-475.

Magalhaes, Y. T., Carvalho, A. N., \& Saraiva, L. A. S. (2011). Práticas gerenciais relacionadas à qualificação de trabalhadores terceirizados: um estudo de caso no setor de mineração. Organizações \& Sociedade, 18(57), 227-244. 
Meirelles, H. L. (2009). Direito Administrativo brasileiro. São Paulo: Malheiros.

Mello, C. A. B. (2010). Curso de Direito Administrativo (27a ed.). São Paulo: Malheiros.

Motta, P. R. (2007). A modernização da administração pública brasileira nos últimos 40 anos. Revista de Administração Pública, 41(esp.), 87-96.

Muta, P. V., Alves, A. C., \& Vergna, J. D. G. (2010). Terceirização trabalhista: aspectos jurídicos e perspectivas legais. Repertório de Jurisprudência IOB, 2(24), 778-790.

Nohara, I. P. (2014). Direito Administrativo (4a ed.). São Paulo: Atlas.

Oliveira, V. A. R. (2012). Interesse público, gestão pública e gestão social: significados e conexões. (Tese de doutorado). Universidade Federal de Lavras, Lavras, MG, Brasil.

Paulo, V., \& Alexandrino, M. (2015). Direito Constitucional descomplicado (14a ed.). São Paulo: Método.

Pazzaglini, M. F. (2008). Princípios constitucionais reguladores da Administração Pública (3a ed.). São Paulo: Atlas.

Pimenta, C. C. (1998). A reforma gerencial do Estado brasileiro no contexto das grandes tendências mundiais. Revista de Administração Pública, 32(5), 173-199.

Rosenbloom, D. H., \& Piotrowski, S. J. (2005). Outsourcing the Constitution and administrative law norms. American Review of Public Administration, 35(2), 103-121.

Silva, P. P. (2011). Terceirização nos serviços públicos. Revista TST, 77(1), 95-130.

Silva, R. A. R., \& Souza, R. C. (2004, setembro). Casos e descasos da terceirização na administração pública: apontamentos, percepções e reflexões em órgãos de Minas Gerais. Anais do Encontro Nacional de Pós-Graduação e Pesquisa em Administração, Curitiba, PR, Brasil, 28.

\section{BY-NC-ND}

